\title{
ORIGINAL ARTICLE Psychiatric manifestations in cerebrotendinous xanthomatosis
}

\author{
MJ Fraidakis ${ }^{1,2}$
}

Cerebrotendinous xanthomatosis (CTX) is a rare and severe, but treatable, inborn disorder of bile acid biosynthesis and sterol storage with autosomal recessive inheritance and variable clinical presentation. CTX treatment consists of chenodeoxycholic acid and must be started as early as possible to prevent permanent disability. Psychiatric manifestations are rare and non-specific, and often lead to significant diagnostic and treatment delay. Therefore, better recognition of the gamut of psychiatric manifestations in CTX can diminish the risk of misdiagnosis and irreversible neurological deterioration. We hereby describe the psychiatric features in CTX. A complete review of all published cases of CTX in the medical literature was undertaken and the case reports with psychiatric presentation were collected and analyzed. We also describe the psychiatric features in relation to the neurological semeiology in six patients with CTX diagnosed at the La Salpêtrière Hospital. We conclude that psychiatric manifestations in CTX follow a bimodal/ bitemporal pattern, appearing early in the disease course in the form of a behavioral/personality disorder associated with learning difficulties or mental retardation, or manifesting in advanced disease in the setting of dementia as rich neuropsychiatric syndromes, such as frontal, orbitofrontal or frontotemporal syndromes of cortico-subcortical dementia encompassing behavioral/personality disturbance, affective/mood disorders or psychotic disorders. Behavioral/personality disturbance in childhood or adolescence, especially when accompanied by learning difficulties, should therefore lead to further investigation to exclude CTX, as early diagnosis and treatment is critical for prognosis.

Translational Psychiatry (2013) 3, e302; doi:10.1038/tp.2013.76; published online 3 September 2013

Keywords: behavior/personality disorder; cerebrotendinous xanthomatosis; chenodeoxycholic acid; cholestanol; psychiatric manifestations; young-onset dementia

\section{INTRODUCTION}

Cerebrotendinous xanthomatosis (CTX) (OMIM 213700) is a rare and severe inborn disorder of bile acid biosynthesis and sterol storage with autosomal recessive inheritance and variable clinical presentation. ${ }^{1-4}$ The enzymatic defect of sterol 27-hydroxylase impairs the synthesis of the bile acids, cholic and chenodeoxycholic, with a resultant overproduction and accumulation of several bile acid synthetic pathway byproducts in large deposits in many organs, including the central nervous system (CNS). ${ }^{4-6}$ Diagnosis is strongly suggested by specific clinical features, such as juvenile cataracts, tendon xanthomas or chronic diarrhea, and is confirmed by the lab finding of elevated cholestanol in the plasma or cerebrospinal fluid, and by molecular genetic analysis. ${ }^{3,4,6}$ Early diagnosis is of paramount importance, as treatment can halt disease progression. ${ }^{7,8}$ The mainstay treatment consists of chenodeoxycholic acid (CDCA) per os administration, $250 \mathrm{mg}$ three times daily. $3,4,7,8$ Cholestanol levels can be further reduced by the addition of a statin, usually simvastatin or pravastatin, but with uncertain evidence-based clinical benefit, apart from the prophylactic effect against atherosclerosis. ${ }^{9}$ Timely therapy is effective in alleviating some of the neurological symptoms, but unfortunately, as a rule, diagnosis is made with a delay of up to many years if ever. ${ }^{10}$

More than 400 cases have been described previously worldwide in the medical literature. ${ }^{10}$ Given the autosomal recessive inheritance mode, higher prevalence has been reported in some closed communities, such as the Sephardic Jews of Morrocan origin. ${ }^{11}$ The pathogenic mechanisms in CTX begin to operate early in life and disease manifestations are usually evident by the second decade. Onset occurs insidiously, with systemic or neurological symptoms and signs. ${ }^{3,4,6}$ Early typical signs are chronic diarrhea, juvenile bilateral cataracts, Achilles (or other) tendon xanthomas, psychomotor retardation, cognitive impairment with learning difficulties or mental retardation, cerebellar ataxia and epilepsy, which can affect up to $50 \%$ of patients. ${ }^{3,4,6,12-16}$ Other late-stage neurological features are pyramidal tract signs with extensor plantar responses, progressive spastic paraplegia, progressive cerebellar ataxia and dysarthria, nystagmus, peripheral polyneuropathy with distal muscle wasting and, more rarely, movement disorders, such as parkinsonism and palatal myoclonus, and in advanced-disease pseudobulbar and bulbar syndromes. ${ }^{4,6,13,14}$ Intellectual deterioration may progress to veritable cortical/subcortical dementia, yet mental function may remain apparently normal in some patients. ${ }^{13}$ Systemic manifestations are premature atherosclerosis with cardiovascular morbidity, pulmonary dysfunction and osteoporosis predisposing to bone fractures. ${ }^{17-19}$ Psychiatric manifestations have been reported only sporadically. ${ }^{14,20-43}$

Magnetic resonance imaging (MRI) is helpful in demonstrating early lesions in the cerebellum, in the form of hyperintensities in the dentate nuclei and hemispheres, and in folia atrophy, on T2weighted images. ${ }^{44,45}$ Other MRI lesions can be seen in the brain stem, often symmetrically in the pyramidal tracts, the medial lemnisci and the inferior olives, whereas supratentorially, slight, non-specific signal alterations are seen periventricularly, always on T2 images. ${ }^{44-46}$ In advanced untreated cases, symmetrical dentate

\footnotetext{
${ }^{1}$ Federation of Neurology, La Salpêtrière Hospital, Groupe Hopsitalier Pitié-Salpêtrière (GHPS), Paris, France and ${ }^{2}$ Department of Neurogenetics, La Salpêtrière Hospital, Groupe Hopsitalier Pitié-Salpêtrière (GHPS), Paris, France. Correspondence: Dr MJ Fraidakis, Fédération de Neurologie, Hôpital de la Salpêtrière, Groupement Hospitalier Universitaire Est Pitié-Salpêtrière (GHPS), Boulevard de l'Hôpital 47-83, 75651 Paris, France.
}

E-mail: matthieu.fraidakis@psl.aphp.fr

Received 24 June 2013; accepted 19 July 2013 
hypointensities have been reported with T1-weighted imaging, suggesting calcium and hemosiderin deposition, also detectable by transcranial ultrasonography. ${ }^{44-46}$ The cerebral cortex and centrum semiovale appear normal on MRI images, similar to that usually seen histologically. ${ }^{13,28,44-46}$ Macroscopically, large granulomatous lipid deposits $(1-2 \mathrm{~cm})$ with extensive demyelination can be found in the cerebellar hemispheres, the cerebellum being most conspicuously affected by lipid deposition, which can otherwise also involve the brain stem and spinal cord. ${ }^{13,28}$ Microscopically, white matter is replaced by neutral fat, needle-like clefts and cystic spaces; foamy vacuolated macrophages and multinucleated giant cells can be found in the affected CNS areas. $^{28}$

Psychiatric and behavioral manifestations in CTX are rare, especially in the younger patients, and are often misattributed to psychiatric disease when grave or are overlooked when subtle. ${ }^{10}$ Personality changes with irritability and aggressivity, depression, delusional syndrome, even catatonia, frank psychosis and suicidal ideation have all been reported in scant reports previously. Dementia often develops in advanced CTX, and in older patients it may be heralded or may coexist with florid psychiatric manifestations. ${ }^{20,24,34}$

We hereby describe the psychiatric manifestations from a cohort of 13 patients with CTX evaluated at the Pitié-Salpêtrière University Hospital. Psychiatric manifestations in the setting of early or advanced dementia in our cohort are described to serve as a counterpoint to the psychiatric picture of younger CTX patients without dementia. A complete review of all published cases of CTX in the medical literature from 1936 to date was also undertaken and the case reports with psychiatric presentation were collected and analyzed. The results from our series are compared with the findings from the review of the medical literature. Conclusions are drawn on the spectrum of psychiatric manifestations in CTX in relation to patient age and disease stage.

\section{MATERIALS AND METHODS}

We reviewed 13 cases of genetically confirmed CTX, diagnosed and followed up at the Neurology Department of the La Salpêtrière University Hospital for the presence of psychiatric manifestations at any stage of the disease history. Patients and their parents were interviewed to obtain the best estimates for lifetime diagnoses. Furthermore, all psychiatric and medical charts, as well as school notes, were collected to confirm the clinical information, both in terms of symptoms and of time course.

A Medline search was done (1968-2012) on CTX. From the reference list of the papers thus collected, we found all articles on the subject, which were published before 1968, as far back as the original publications of Schneider (1936) and van Bogaert et al. ${ }^{47,48}$ monography. These papers were collected from medical libraries and were reviewed thoroughly on the basis of the documentation of CTX case reports. Original and review articles in English, French, Italian, Spanish, German and Dutch were read. Articles written in Japanese were not reviewed, but their abstracts were taken into account. Although the occasional review articles in Hebrew and Russian were not read, they did not contain any case reports. From the review of the above mentioned medical literature, we managed to collect data on 425 cases, which is most probably an underestimate of the worldwide disease prevalence. Although many case descriptions were poor in information, we extracted the case reports that contained even the slightest hint of a psychiatric semeiology. In our analysis of the psychiatric manifestations of CTX, however, we did not include the cases that were simply described as having developed learning difficulties, mental retardation or dementia. Nevertheless, we included all case reports wherein psychiatric manifestations were mentioned in the setting of CTX-related dementia.

\section{Case reports (La Salpêtrière Hospital)}

Early psychiatric manifestations (not associated with dementia)

Patient 1 (P1). The 24-year-old male patient was born to nonconsanguineous parents. Psychomotor development was normal. The ability to read was acquired normally. At the age of 6 years, frequent falls, clumsiness and learning difficulties in writing, spelling and arithmetic were noticed. He began attending the local Child Development Center at the end of first grade and attended regular sessions with a reading specialist. Interpersonal relational problems and behavioural disturbance were noticed at elementary school. He was reported to be hyperactive, impulsive and sometimes violent. At the age of 13 years, he was hospitalized after an episode of aggressive behavior towards his mother during a family quarrel when he threatened her with a knife. Psychiatric diagnoses at adolescence were borderline intelligence, attention-deficit hyperactivity disorder, predominant hyperactive-impulsive subtype and oppositional-defiant disorder, and no pharmacologic treatment was administered. His high-school education was disorganized and underachieving because of his psychiatric problems and further intellectual decline. His behavioral disturbance with irritability, aggressivity and oppositional behavior persisted throughout adolescence. He showed indifference and aggressivity towards his mother, non-adherence to rehabilitation orders and negligence of basic hygiene. At 21 years of age, neuropsychological testing revealed diminished global cognitive efficiency, difficulties in abstract reasoning, deficit in attention and dysexecutive syndrome affecting the instrumental capacities (Mini Mental Scale (MMS): 21/29; Frontal Assessment Battery (FAB) $\left.{ }^{49,50}: 16 / 18\right)$. At physical and neurological examination, elongated facies, pes cavus and cerebellar ataxia were found, and electroneuromyography evidenced mild peripheral neuropathy. MRI scanning showed discrete cerebellar and parieto-occipital white matter hyperintensities. Cholestanol levels were abnormally high and genetic analysis found mutation of the CYP27 alleles in a compound heterozygous state (E6:R395C/E8:R479C). In retrospect, his mother remarked that he had suffered from chronic diarrheas since early childhood. Standard treatment resulted in marked improvement of his psychiatric condition. ${ }^{8}$

Patient 2 (P2). She is the 19-year-old sister of P1. Psychomotor development was normal. Her medical history was non-specific, except for pes cavus with hammer toes discovered at the age of 7 years, as well as chronic diarrhea since childhood. During school years, the patient was active in sports but was underperformed academically, and exhibited oppositional behaviors and deficits in attention. She received methylphenidate (10-20 mg per day) for attention-deficit hyperactivity disorder from ages 9 to 11 years. The treatment was discontinued because of worsening of impulsivity, aggressiveness and cognitive decline, forcing her to leave school. Neurological examination and electroneuromyography found mild signs of sensorimotor axonal peripheral neuropathy. Results of brain MRI scanning and ophthalmological examinations were normal. Cholestanol levels were abnormally high and genetic analysis found mutation of the CYP27 alleles in a compound heterozygous state (E6:R395C/E8:R479C). The diagnosis of CTX was made after her brother's diagnosis, when she was 17 years old. Standard treatment resulted in substantial improvement of her psychiatric condition.

Patient 3 (P3). The patient is a sister of P4. She was hospitalized in her twenties for a psychiatric illness that was characterized as psychotic episode. Bilateral Achilles tendon xanthomas were noticed at clinical examination. Retrospective psychiatric evaluation revealed only learning difficulties in childhood and adolescence with poor scholastic performance. The patient was lost to follow-up and did not receive specific treatment for CTX. Cholestanol levels were abnormally high and, similar to her brother, she was a carrier of the the pathogenic IVS4-1G > A mutation in the CYP27A1 gene in a homozygous state.

\section{Late psychiatric manifestations (associated with dementia)}

Patient 4 (P4). The patient is a 50-year-old male, born to nonconsanguineous parents. Psychomotor development was normal. He has several siblings, among whom one sister was with a psychiatric illness and Achilles tendon xanthomas diagnosed with CTX. His overt disease history began at 13 years of age with a grand mal seizure. At 44 years, irritability with general hyperhidrosis was interpreted as anxiety/depression syndrome. In the following months, his condition progressed with apparition of gait instability, dysarthria, swallowing problems and apathy. Physical examination at that time confirmed gait ataxia, dysarthria, hyperreflexia of deep tendon reflexes and psychomotor slowing. MRI imaging revealed midbrain and dentate nuclei hyperintensities at T2 and FLAIR. Cholestanol levels were elevated and the diagnosis was confirmed by the identification of the pathogenic IVS4-1G>A mutation in the CYP27A1 gene in a homozygous state. Treatment with CDCA was initiated at age 44 years. Despite treatment, neurologic signs did not improve and he was markedly apathic when last seen. 
Table 1. Clinical description of CTX patients with psychiatric manifestations examined and diagnosed at the La Salpêtrière Hospital

\begin{tabular}{llcccccclll}
\hline & Gender & Origin & $D$ (years) & $X$ (years) & $N$ (years) & $\Psi$ & $\Psi^{*}$ & $\Psi_{S}$ & $\Psi_{D}$ (axis) \\
\hline P1 & M & Fr-Sp & 22 & 25 & ado & 6 & Yes $^{*}$ & Aggr., irritability, ADHD, ODD & Behavioral/personality & LD/MR \\
P2 & F & Fr-Sp & 17 & 20 & 16 & 16 & Yes* & Aggr., irritability, ADHD, ODD & Behavioral/personality & LD/MR \\
P3 & F & French & 20 & 35 & ch. & ado & No & Aggressivity, psychosis & Psychotic \\
P4 & M & French & 48 & 50 & 13 & 44 & No & Irritability, anxiety/depr., apathy & Mood/affective \\
P5 & F & French & 45 & 49 & $7 \mathrm{~m}$ & 43 & No & Anxiety/depression & Dementia \\
P6 & F & French & 58 & 58 & ch. & 50 & No & Irritability, emotional lability & Mood/affective & Meod/affective \\
\hline
\end{tabular}

Abbreviations: ADHD, attention-deficithyperactivity disorder; ado, adolescence not specified; Aggr., aggressive; ch, childhood not specified; Cog, psychiatric manifestations associated with LD, MR or dementia; CTX, cerebrotendinous xanthomatosis; D, age at diagnosis; Depr., depression; F, female; Fr., French; LD, learning difficulties; M, male; MR, mental retardation; $N$, age at neurological debut; ODD, oppositional-defiant disorder; Sp., Spanish; $X$, age at last examination; $\Psi$, age at psychiatric debut; $\Psi^{*}$, psychiatric initial presentation, psychiatric first referral of CTX or none of these; $\Psi_{S}$, psychiatric semeiology; $\Psi_{\mathrm{D}}$ (Axis), type of psychiatric disorder.

Patient 5 (P5). The patient is a 49-year-old female. Psychomotor development was normal. Epilepsy with petit mal seizures appeared at the age of 7 months. She was schooled until the sixth class and later followed special education because of learning difficulties. She recalls that her gait problems began at the age of 30 years and progressed with time. At 42 years, a pyramidal syndrome with spasticity of all members was found at clinical examination and her gait deteriorated more rapidly thereafter. At 43 years, she was unemployed, on invalidity pension, living with her parents and suffering from depression attributed to her sorrow over her husband's death. Clinical examination revealed spastic paraparesis with gait ataxia, hyperreflexia of deep tendon reflexes with bilateral Babinski and Hoffmann signs, and mental retardation (IQ: 50; MATTIS: 118/ 144). At the age of 44 years, neuropsychologic testing scores were $21 / 30$ and $10 / 18$ for MMS and FAB, respectively. Ultimately, metabolic screening revealed elevated cholestanol and the diagnosis of CTX was confirmed with genetic analysis. The patient did not have visible tendon xanthomas. MRI imaging demonstrated bilateral cerebellar white matter hyperintensities, periventricular white matter hyperintensities, and diffuse cortical and subcortical atrophy subtentorially and supratentorially. A combinated regimen of pravastatin ( $20 \mathrm{mg}$ per day) and CDCA ( $250 \mathrm{mg}$ three times daily) was initiated at 45 years, and the patient was followed up. The patient experienced a substantial and quantifiable benefit from treatment. On a follow-up, 6 months later, MMS was $25 / 30$ and FAB was 12/18, the remaining neurologic status being stable. On a second follow-up 1 year after the last, FAB was $13 / 18$. On a third follow-up 9 months later, the patient reported sustained improved gait and cognitive benefits (better concentration capacity and less apragmatism). MMS was 28/30 and FAB was $15 / 18$.

Patient 6 (P6). A 56-year-old female patient of French descent born to non-consanguineous parents. She was operated several times during childhood because of bilateral cataract. Gait difficulties and dysequilibrium appeared in her thirties and worsened steadily thereafter during the course of 20 years, resulting in severe spastic paraparesis and ataxia that rendered the patient wheel-chair bound. Along the same timeline, signs of dementia appeared and progressed (anterograde and retrograde amnesia, frontal syndrome signs, emotional lability and irritability). At the age of 56 years, the patient was hospitalized. Neuropsychiatric testing confirmed global dementia with MMS at $21 / 30$ and dysexecutive syndrome with $F A B$ at $12 / 18$. MRI imaging revealed diffuse cerebral cortical and subcortical atrophy, as well as cerebellar cortical atrophy, diffuse moderate leukoencephalopathy, hyperintensities of the corticospinal tract at the capsular and cerebral peduncle levels, and T1-T2-FLAIR hypointensities of the dentate nuclei, corresponding to calcifications. Biochemical analysis revealed elevated cholestanol and sterol precursors of cholesterol, and the diagnosis of CTX was confirmed with genetic analysis. Treatment with CDCA was initiated at 56 years and resulted in alleviation of psychiatric symptoms, but neurological signs did not improve.

\section{RESULTS}

In the cohort of 13 patients at the La Salpêtrière Hospital, 6 patients exhibited psychiatric symptoms at some point in the disease course, and in half of them psychiatric symptoms occurred in the setting of organic dementia (Table 1). Out of the three younger patients without dementia at the time of psychiatric symptoms (P1, P2 and P3), only two siblings had a purely psychiatric presentation of CTX, occurring in their early-to-middle adolescence and associated with mild cognitive and intellectual decline without mental retardation (P1 and P2). Notably, they both presented with behavioral and personality disturbance, initially diagnosed as attention-deficit hyperactivity disorder and oppositional-defiant disorder. Agressivity, irritability and insubordination was a major component of their psychiatric tableau as has been seen in other CTX cases we reviewed. ${ }^{21,22}$ Both siblings received standard treatment (per os administration of Chenofalk, $250 \mathrm{mg}$ three times daily), and follow-up psychiatric examination confirmed a clear and substantial improvement of their psychiatric condition. ${ }^{8}$ Standard treatment of the three older patients with CTX-related organic dementia also led to the alleviation of psychiatric symptomatology and/or mild improvement of cognitive status (P4, P5 and P6). In two families testing of the members at risk proved the diagnosis in a second sibling, and in one family this led to timely treatment with beneficial results for the psychiatric condition of the patients (P1 and P2).

Psychiatric manifestations in CTX have only been described in sporadic case reports and in only one case series. ${ }^{20}$ In total, we found that 54 patients of the 425 CTX cases published in the medical literature in the period 1937-2012 have had psychiatric manifestations ranging from personality changes and behavioral disorder to frank affective and psychotic disorders ${ }^{20-43}$ (Tables 2 and 3). This amounts to an incidence of $12.7 \%$ for psychiatric manifestations in the CTX population. This figure is informative but only approximative. The true figure could be higher because of underreporting of psychiatric signs in the poorly described case reports. ${ }^{10}$ It could even be lower because of underdiagnosis of CTX in general. ${ }^{10}$

There was significant variation of psychiatric phenotype in the above mentioned 54 cases (Tables 2 and 3). The most common manifestation was behavioral/personality disorder ( $n=24,5.6 \%)$ followed by mood/affective disorder $(n=10,2.3 \%)$ and psychosis $(n=5,1.2 \%)$, whereas there was only one case report of catatonia in the setting of CTX $(n=1,0.2 \%)$ (Figure 1). Patients with mood/affective disorders reportedly suffered from depression, except for one patient who suffered from dysthymia (Tables 2 and 3).

It was possible to determine the approximate age of onset and mode of disease onset for 34 out of the total of 54 patients found in the bibliography, with CTX and psychiatric manifestations at some point in the disease course (Tables 2 and 3). As expected, in most cases (26 out of these 34 ) CTX-related symptoms or signs led to hospital referral before the age of 26 years, as usually CTX is an inborn metabolic disease of childhood onset. Pure psychiatric presentation of CTX occured most often during childhood and never occurred after the age of 26 years (Tables 2 and 3, Figures 2 
Table 2. Clinical description of CTX patients with psychiatric manifestations drawn from the medical literature

\begin{tabular}{|c|c|c|c|c|c|c|c|c|c|c|c|}
\hline Reference & $P$ & G & Origin & $D$ & $x$ & N & $\Psi$ & $\Psi^{*}$ & $\Psi_{D}$ (Axis) & $\operatorname{Cog}$ & $P$ \\
\hline Philippart and van Bogaert ${ }^{23}$ & P1 & $\mathrm{F}$ & Flemish & 42 & 42 & 10 & 10 & Yes* & Behavioral/personality & MR & P1 \\
\hline Shapiro $^{24}$ & P2 & M & US (Caucasian) & 45 & 50 & 34 & 49 & No & Mood/affective & Dementia & P2 \\
\hline Burnstein et al. ${ }^{25}$ & P3 & M & US (Caucasian) & 42 & 42 & 32 & 32 & No & NS & Dementia & P3 \\
\hline Laurent et al. ${ }^{26}$ & P4 & $\mathrm{F}$ & French & 43 & 43 & 40 & 43 & No & Behavioral/personality & Dementia & P4 \\
\hline Laurent et al. ${ }^{26}$ & P5 & M & French & 39 & 39 & 29 & 39 & No & Behavioral/personality & Dementia & P5 \\
\hline Laurent et al. ${ }^{26}$ & P6 & M & French & 28 & 28 & 23 & 9 & Yes* & Behavioral/personality & MR & P6 \\
\hline Laurent et al. ${ }^{26}$ & P7 & $\mathrm{F}$ & French & 49 & 49 & 8 & $<49$ & No & Mood/affective & Dementia & P7 \\
\hline Berginer et al. ${ }^{20}$ & P8 & M & Israel & 42 & 43 & 22 & $<32$ & Yes & Behavioral/personality & MR & P8 \\
\hline Berginer et al. ${ }^{20}$ & P9 & M & Israel & 25 & 18 & 18 & 37 & No & Psychosis & Dementia & P9 \\
\hline Berginer et al. ${ }^{20}$ & P10 & M & Israel & 22 & 12 & 12 & 27 & No & Catatonia & $\mathrm{MR}$ & P10 \\
\hline Berginer et al. ${ }^{20}$ & P11 & $\mathrm{F}$ & Israel & 32 & 32 & 12 & 22 & Yes & Behavioral/personality & MR & P11 \\
\hline Wevers et al. ${ }^{27}$ & $\mathrm{P} 12$ & $\mathrm{~F}$ & Dutch & 37 & 37 & 25 & 25 & Yes* & NS & MR & P12 \\
\hline Soffer et al. ${ }^{28}$ & P13 & $\mathrm{F}$ & Morrocan Jewish & 30 & 37 & $<5$ & 24 & Yes & Behavioral/personality & $\mathrm{MR}$ & P13 \\
\hline Verrips et al. ${ }^{29}$ & P14 & $\mathrm{F}$ & Dutch & 33 & 35 & 17 & 17 & No & NS & $\mathrm{MR}$ & P14 \\
\hline Sperhake et al. ${ }^{30}$ & P15 & M & Germany & 52 & 52 & $<6$ & $<6$ & Yes* & Behavioral/personality & LD & P15 \\
\hline Sugama et al. & P16 & $\mathrm{F}$ & Japanese & 44 & 44 & 38 & 38 & No & Behavioral/personality & Dementia & P16 \\
\hline Dotti et al. ${ }^{32}$ & P17 & M & Italian & 39 & $?$ & $?$ & $?$ & $?$ & Behavioral/personality & $?$ & P17 \\
\hline Dotti et al. $^{32}$ & P18 & $\mathrm{F}$ & Italian & 48 & ? & ? & ? & ? & Psychosis & ? & P18 \\
\hline Dotti et al. ${ }^{32}$ & P19 & M & Italian & 52 & $?$ & $?$ & $?$ & $?$ & Mood/affective & $?$ & P19 \\
\hline Dotti et al. ${ }^{32}$ & P20 & $\mathrm{F}$ & Italian & 32 & ? & ? & ? & ? & Behavioral/personality & ? & P20 \\
\hline Dotti et al. ${ }^{32}$ & P21 & M & Italian & 39 & ? & ? & ? & ? & $\begin{array}{l}\text { Psychosis } \\
\end{array}$ & ? & P21 \\
\hline Dotti et al. ${ }^{32}$ & P22 & $\mathrm{F}$ & Italian & 39 & $?$ & $?$ & $?$ & $?$ & Behavioral/personality & $?$ & P22 \\
\hline Dotti et al. ${ }^{32}$ & P23 & $\mathrm{F}$ & Italian & 42 & $?$ & $?$ & $?$ & $?$ & Behavioral/personality & $?$ & P23 \\
\hline Dotti et al. ${ }^{32}$ & P24 & $\mathrm{F}$ & Italian & 47 & $?$ & $?$ & $?$ & $?$ & behavioral/personality & $?$ & P24 \\
\hline Dotti et al. ${ }^{32}$ & P25 & M & Italian & 54 & $?$ & $?$ & $?$ & $?$ & Mood/affective/depr. & $?$ & P25 \\
\hline Dotti et al. ${ }^{32}$ & P26 & M & Italian & 51 & $?$ & $?$ & $?$ & $?$ & Psychosis & $?$ & P26 \\
\hline Dotti et al. ${ }^{32}$ & P27 & $\mathrm{F}$ & Italian & 37 & $?$ & $?$ & $?$ & $?$ & Psychosis & $?$ & P27 \\
\hline Lee et $a l^{21}$ & P28 & $\mathrm{F}$ & Taiwan & 31 & 41 & 6 & 29 & Yes & Mood/affective & $\mathrm{MR}$ & P28 \\
\hline Lee et $a l^{21}$ & P29 & M & Taiwan & 32 & 43 & $<5$ & Ado & Yes* & Behavioral/personality & $\mathrm{MR}$ & P29 \\
\hline Lee et $a l^{21}$ & P30 & $\mathrm{F}$ & Taiwan & 37 & 48 & $<5$ & Ado & Yes* & Behavioral/personality & MR & P30 \\
\hline Grandas et al..$^{14}$ & P31 & $\mathrm{F}$ & Spain & 39 & 51 & 26 & 26 & Yes* & Mood/affective & MR & P31 \\
\hline Bartholdi et al. ${ }^{33}$ & P32 & $\mathrm{F}$ & Swiss & 51 & 51 & 6 & 49 & No & Mood/affective & Dementia & P32 \\
\hline Guyant-Maréchal et al. & P33 & M & French & 53 & 53 & 15 & 44 & Yes & Behavioral/personality & Dementia & P33 \\
\hline Siman-Tov et al. ${ }^{35}$ & P34 & M & Israel (Ashkenazi) & 29 & 29 & 4 & 29 & No & Behavioral/personality & MR & P34 \\
\hline Price Evans et al. ${ }^{22}$ & P35 & $\mathrm{F}$ & Saudi & 22 & 17 & 10 & 10 & Yes* & Behavioral/personality & MR & P35 \\
\hline Price Evans et al. ${ }^{22}$ & P36 & M & Saudi & 30 & 18 & 10 & 18 & No & Behavioral/personality & MR & P36 \\
\hline Gonzalez-Cuyar et al. ${ }^{36}$ & P37 & $\mathrm{F}$ & USA & 49 & 49 & ? & $40 \mathrm{~s}$ & No & NS & MR & P37 \\
\hline de la Fuente et $a l^{37}$ & P38 & M & Spain & 52 & 40 & 18 & 18 & Yes* & Behavioral/personality & Dementia & P38 \\
\hline Szlago et $a l^{38}$ & P39 & M & Argentina & 17 & 17 & 0 & Ado & Yes & Behavioral/personality & MR & P39 \\
\hline Zacherl et al. ${ }^{39}$ & P40 & $\mathrm{F}$ & Germany & 44 & 44 & 20 & $?$ & No & Mood/affective & Dementia & P40 \\
\hline Filippi et al. ${ }^{40}$ & P41 & M & Chile & 39 & 20 & $<20$ & Ado & No & Mood/affective & Dementia & P41 \\
\hline Bonnot et al. ${ }^{8}$ & P42 & M & French-Spanish & 23 & 24 & 6 & $<10$ & Yes & Behavioral/personality & LD & P42 \\
\hline Bonnot et al. ${ }^{8}$ & P43 & $\mathrm{F}$ & French-Spanish & 17 & 19 & 7 & $<10$ & Yes & Behavioral/personality & LD & P43 \\
\hline Chang et al. ${ }^{41}$ & P44 & M & Chinese & 24 & 29 & $?$ & $?$ & No & Anxiety & MR & P44 \\
\hline Chang et al. ${ }^{41}$ & P45 & $\mathrm{F}$ & Chinese & 31 & 48 & ? & ? & No & Mood/affective & Dementia & P45 \\
\hline de la Fuente et $a l^{42}$ & P46 & $?$ & Spain & $?$ & $?$ & $?$ & ? & $?$ & NS & $?$ & P46 \\
\hline de la Fuente et al..$^{42}$ & P47 & $?$ & Spain & $?$ & $?$ & $?$ & ? & ? & NS & $?$ & P47 \\
\hline de la Fuente et al. ${ }^{42}$ & P48 & ? & Spain & ? & ? & ? & ? & ? & NS & ? & P48 \\
\hline de la Fuente et al..$^{42}$ & P49 & ? & Spain & ? & ? & $?$ & ? & ? & NS & $?$ & P49 \\
\hline de la Fuente et al. $^{42}$ & P50 & ? & Spain & ? & ? & ? & ? & ? & NS & ? & P50 \\
\hline de la Fuente et al. $^{42}$ & P51 & $?$ & Spain & $?$ & $?$ & $?$ & $?$ & $?$ & NS & $?$ & P51 \\
\hline de la Fuente et al. ${ }^{42}$ & P52 & ? & Spain & $?$ & $?$ & ? & ? & ? & NS & ? & P52 \\
\hline de la Fuente et al. ${ }^{42}$ & P53 & $?$ & Spain & $?$ & $?$ & $?$ & $?$ & $?$ & NS & $?$ & P53 \\
\hline de la Fuente et al. $^{42}$ & P54 & ? & Spain & ? & ? & ? & ? & ? & NS & ? & P54 \\
\hline
\end{tabular}

Abbreviations: Ado, adolescence not specified; Cog, psychiatric manifestations associated with LD, MR or dementia; CTX, cerebrotendinous xanthomatosis; $D$, age at diagnosis; depr., depression; F, female; LD, learning difficulties; M, male; MR, mental retardation; $N$, age at neurological debut; NS, not specified; $X$, age at last examination; $\Psi$, age at psychiatric debut; $\Psi^{*}$, psychiatric initial presentation, psychiatric first referral of CTX or none of these; $\Psi_{S}$, psychiatric semeiology; $\Psi_{\mathrm{D}}$ (Axis), type of psychiatric disorder.

and 3). From the 34 out of the 54 patients for whom records on the age of onset and mode of onset were found, 17 patients had been brought to clinical attention because of psychiatric manifestations irrespective of patient age or coexisting neurological, ocular or dermatological CTX manifestations (Table 2, colorcoded red). However, in only 9 out of these 17 CTX cases were psychiatric manifestations the first sign of disease that led to clinical evaluation, and this occurred always at a young age (6-26 years; Figure 2, Table 2, marked with an ${ }^{*}$ in column $\Psi^{*}$ ). It must be pointed out that cognitive decline or established mental retardation coexisted in seven out of these nine cases at the time of psychiatric presentation, whereas in the remaining two cases psychiatric symptomatology occurred in the absence of overt cognitive decline. In the remaining 8 out of the above mentioned 17 cases, psychiatric manifestations had appeared at an older age, and a more advanced disease stage and mental retardation or dementia were already established (Table 2, color-coded red, not marked with ${ }^{*}$ in column $\left.\Psi^{*}\right)$. In the other 17 out of the above mentioned 34 CTX cases, psychiatric manifestations were a late feature of the disease in the setting of established CTX with either mental retardation or dementia, and in most cases the diagnosis had been made many years previously; hence, the psychiatric symptomatology did not aid the clinical diagnosis (Table 2, not color-coded in column $\Psi^{*}$ ). The gamut of psychiatric pathology in these patients was more broad, encompassing affective/mood disorders, psychotic disorders and psychiatric 
Table 3. Detailed description of psychiatric history and manifestations of CTX patients drawn from the medical literature

Psychiatric symptoms and signs (age)

P1: (BEHAVIORAL/PERSONALITY disorder) Behavioral/personality disorder, $(<10)$

P2: (MOOD/AFFECTIVE disorder) Depressive episode, suicidal ideation and threats, aggressivity, assault threats, disinhibition, poor impulse control, fecal incontinence (49)

P3: NS (32)

P4: (BEHAVIORAL/PERSONALITY disorder) Apathy, spasmodic laughter/cry (43)

P5: (BEHAVIORAL/PERSONALITY disorder) Behavioral alteration, logorrhea, psychomotor excitation, distractibility, fleeting ideas, emotional lability, no spasmodic laughter/cry (39)

P6: (BEHAVIORAL/PERSONALITY disorder) Behavioral/personality disorder (childhood), psychiatric institution (23)

P7: (MOOD/AFFECTIVE disorder) Mood instability, affective disorder, predominantly depressive periods, phases of agitation/excitation even aggressivity (49)

P8: (BEHAVIORAL/PERSONALITY disorder) Behavioral/personality disorder, irritability, agitation (6 psychiatric hospitalizations before 32 ) personality disturbance, hypersexuality?(32) paranoid id., suicidal (41)

P9: (PSYCHOSIS) Psychosis atypical, paranoid delusion (37)

P10: (CATATONIA) Catatonia reactive to family stress?, akinetic, mute, fixed postures, urinary-fecal incontinence (27)

P11: (BEHAVIORAL/PERSONALITY disorder) Aggressivity, agitated, required many hospitalizations (22)

P12: NS (25)

P13: (BEHAVIORAL/PERSONALITY disorder) Behavioral/personality disorder, aggressivity, destructive behavior (24)

P14: NS (between 17-33)

P15: (BEHAVIORAL/PERSONALITY disorder) Behavioral/personality disorder (early childhood)

P16: (BEHAVIORAL/PERSONALITY disorder) Behavioral/personality disorder, lack of affection and neglect towards family, restlessness, disinhibition, apathy, abulia, PREDEMENTIA (38-40)

P17: (BEHAVIORAL/PERSONALITY disorder) Behavioral/personality disorder, behavioral changes

P18: (PSYCHOSIS) Psychosis

P19: (MOOD/AFFECTIVE disorder) Depression

P20: (BEHAVIORAL/PERSONALITY disorder) Behavioral/personality disorder, Behavioral changes

P21: (PSYCHOSIS) Psychosis

P22: (BEHAVIORAL/PERSONALITY disorder) Behavioral/personality disorder, Behavioral changes

P23: (BEHAVIORAL/PERSONALITY disorder) Behavioral/personality disorder, Behavioral changes

P24: (BEHAVIORAL/PERSONALITY disorder) Behavioral/personality disorder, Behavioral changes

P25: (MOOD/AFFECTIVE disorder) Depression

P26: (PSYCHOSIS) Psychosis

P27: (PSYCHOSIS) Psychosis

P28: (MOOD/AFFECTIVE disorder) Depression, irritability, insomnia, crying spells, poor appetite, agitated; bullied constantly by her siblings with CTX since early teens (29)

P29: (BEHAVIORAL/PERSONALITY disorder) Behavioral/personality disorder, aggressivity towards sister (adolescence)

P30: (BEHAVIORAL/PERSONALITY disorder) Behavioral/personality disorder, Aggressivity towards sister (adolescence)

P31: (MOOD/AFFECTIVE disorder) Depression ( $>26,26-37)$

P32: (MOOD/AFFECTIVE disorder) Depression severe (49)

P33: (BEHAVIORAL/PERSONALITY disorder) Behavioral/personality disorder, poor judgment, self-neglect, altered sexual behavior, dysexec, irritability, anxiety (44) PERSONALITY disturbance profound, breakdown in social behavior (53)

P34: (BEHAVIORAL/PERSONALITY disorder) Behavioral/personality disorder, spasmodic laughter

P35: (BEHAVIORAL/PERSONALITY disorder) Behavioral/personality disorder, BEHAVIORAI disorder, aggressivity, irritability, awake at nights, anxiety, fight and hitting and hitting people (10)

P36: (BEHAVIORAL/PERSONALITY disorder) Behavioral/personality disorder, odd behavior could lose his job, but no aggressivity (> 18)

P37: NS (40s)

P38: (BEHAVIORAL/PERSONALITY disorder) Behavioral/personality disturbance at military, introverted (adolescence), paranoid delusions, undifferentiated schizophrenia and schizoid personality disturbance (20-40)

P39: (BEHAVIORAL/PERSONALITY disorder) Behavioral/personality disorder, ADHD (late childhood, adolescence)

P40: (MOOD/AFFECTIVE disorder) Depression, benzodiazepine abuse, suicidal ideation

P41: (MOOD/AFFECTIVE disorder) Mood/affective, bipolar disorder, schizophrenia

P42: (BEHAVIORAL/PERSONALITY disorder) Behavioral/personality disorder, aggressivity, irritability

P43: (BEHAVIORAL/PERSONALITY disorder) Behavioral/personality disorder, aggressivity, irritability

P44: (MOOD/AFFECTIVE disorder) Anxiety

P45: (MOOD/AFFECTIVE disorder) Dysthymia

P46: NS

P47: NS

P48: NS

P49: NS

P50: NS

P51: NS

P52: NS

P53: NS

P54: NS

Abbreviations: ADHD, attention-deficit hyperactivity disorder; CTX, cerebrotendinous xanthomatosis; NS: not specified. In parentheses, age at onset of psychiatric symptomatology/semeiology.

manifestations typical of subcortical dementia, which, in some cases, were compatible to a clinical diagnosis of frontotemporal dementia (Figure 4).

Documentation of the type of psychiatric diagnosis existed for 41 out of the total of 54 patients found in the bibliography, with CTX and psychiatric manifestations at some point in the disease course (Tables 2 and 3). Behavioral/personality disorder was the most frequent psychiatric manifestation in the small group of young CTX patients with pure psychiatric presentation $(n=9)$ of
CTX, whereas in the larger group of CTX patients with nonpsychiatric presentation $(n=32)$ of CTX it was as frequent as all the other psychiatric manifestations together (Figure 3). For 31 out of the 41 CTX cases with documentation of the type of psychiatric diagnosis, there was also available information on its age of onset (Figure 4). Behavioral/personality disorder was the most frequent psychiatric manifestation in all age groups, but especially so in patients younger than 26 years, followed by mood/affective disorder. In patients older than 26 years, psychiatric pathology was 
more complex, with richer semeiology often in the context of predementia/dementia (Figure 4).

In conclusion, based on the 425 CTX case reports we reviewed, the overall incidence of psychiatric manifestations was $12.7 \%$, whereas only 9 CTX cases, for which documentation was adequate to allow further analysis, presented with essentially psychiatric symptoms early in the disease course and in the absence of overt neurological disease (overall incidence $2.5 \%$ ). In seven out of nine of these cases, the manifestation of a pure psychiatric presentation was behavioral/personality disturbance (overall incidence $1.7 \%$ ). Interestingly, all seven CTX patients, with premonitory psychiatric manifestations in the form of behavioral/personality disorder, were younger than 18 years (range 6-18 years) and all suffered from learning difficulties or mental retardation (Tables 2 and 3). It is concluded therefore that psychiatric manifestations in CTX follow a bimodal/bitemporal pattern. They appear (a) either early in the disease course, that is, during childhood or adolescence, in the form of a behavioral/personality disorder associated with learning difficulties or mental retardation, or (b) they manifest in advanced disease in older patients, often in the context of dementia as rich neuropsychiatric syndromes, such as frontal, orbitofrontal or frontotemporal syndromes of cortico-subcortical dementia encompassing behavioral/personality disturbance, affective/mood disorders and/or psychotic disorders.

\section{DISCUSSION}

CTX (also known as sterol 27-hydroxylase deficiency, cholestanolosis, van Bogært-Scherer-Epstein disease or simply van Bogært's disease) is a rare, inborn neurometabolic disorder of bile acid biosynthesis and sterol storage with autosomal recessive inheritance and variable clinical presentation. ${ }^{1-5,23,26,49-53}$ The mutated gene, the sterol 27-hydroxylase gene (CYP27), on the 2q33ter locus, codes for a mitochondrial cytochrome P450, which associates with two protein cofactors (adrenodoxin and adrenodoxin reductase) and catalyzes the hydroxylation at position C27 of the side chain of sterol intermediates, which constitutes the first step in their oxidative cleavage. ${ }^{5,54-57}$ More than 50 different mutations of the gene have been described most of them within the adrenodoxin-binding and the hemebinding sites of the enzyme. ${ }^{43,58-64}$ As a consequence, CDCA synthesis is deficient and so is the negative feedback that CDCA exerts on cholesterol synthesis, with resultant increase in cholesterol synthesis and shunting of cholesterol towards cholestanol ( $5 \alpha$-dihydrocholesterol) and other bile alcohol synthesis byproducts. ${ }^{5,51-58,65}$ Accumulation of cholestanol, as well as cholesterol and various bile alcohols, in large deposits in many organs, particularly in the CNS, tendons, vascular system and lungs, is the pathophysiological mechanism behind CTX. ${ }^{5,51,52,54,65-69}$ In the brain, cholestanol deposition far exceeds that of other sterols, ultimately comprising up to $30 \%$ of total sterols in the cerebellum. ${ }^{36,54,70}$ Interestingly, despite increased cholesterol synthesis, plasma total cholesterol remains below or within the normal-range byproducts. ${ }^{5,49,51-58,70}$ Laboratory diagnosis rests on the findings of elevated cholestanol in the plasma and cerebrospinal fluid, and the presence of bile alcohols (such as lathosterol, $7 \alpha$-hydroxylated bile acids and so on) and bile alcohol glycuronides in the plasma and/or urine. ${ }^{51,52,63,64,70}$ In bile, cholestanol is increased but CDCA is virtually absent. ${ }^{51,52,63,64,70}$ Diagnosis is confirmed by mutation analysis, and genetic counseling is necessary for at-risk relatives, as appropriate treatment can alleviate symptoms and slow disease progression in symptomatic patients, and, most importantly, prevent or minimize disability in asymptomatic homozygotes. ${ }^{43,59}$ The mainstay treatment consists of CDCA (Chenofalk) oral supplementation, $250 \mathrm{mg}$ three times daily, which is the lacking bile acid that reinstitutes the negative feedback and balance in the cholesterol and bile acid synthetic pathways, respectively, and normalizes cholestanol levels in the blood. , $^{3,6,70-72}$ Cholestanol levels can be further reduced by the addition of a statin, usually simvastatin or pravastatin, but without an evidence-based clinical benefit. ${ }^{9,70-73}$ Treatment is effective in that it can alleviate some constitutional, neurologic and even psychiatric symptoms. ${ }^{4,6-8,70-80}$ Electrophysiological, neuropsychological and neuroradiological evaluation results support the notion that timely and adequate specific treatment may partially reverse neural tissue damage in the CNS and peripheral nervous system. ${ }^{41,72-80}$

More than 400 cases have been described previously worldwide in the medical literature, and psychiatric manifestations of CTX have been reported only rarely and sporadically. ${ }^{20-43}$ To date, no comprehensive review of the psychiatric manifestations of CTX has been published. Psychiatric manifestations in CTX present a variability that reflects the variability of the rest of CTX semeiology. These encompassed behavioral/personality disorders, affective/ mood disorders, psychotic disorders and dementia-associated psychopathology (Tables 2 and 3). We found that psychiatric manifestations in CTX follow a bimodal/bitemporal pattern, that is, they would either appear early in the disease course in the form of a behavioral/personality disorder associated with learning difficulties or mental retardation, or they would manifest in advanced disease in the context of dementia as rich neuropsychiatric syndromes, such as frontal, orbitofrontal or frontotemporal syndromes of cortico-subcortical dementia encompassing affective/mood disorders, psychotic disorders or behavioral/ personality disturbance (Tables 2 and 3 ).

Unfortunately, many of the sporadic cases in the medical literature were poorly documented. The Dotti et al. ${ }^{32}$ and the de la Fuente et al. ${ }^{42}$ series comprised, respectively, 11 and 9 patients with psychiatric symptoms, yet these were presented monolectically and the evaluation of their importance and temporal correlation with non-psychiatric manifestations was not possible. Among 13 CTX patients with ocular signs scrutinized by Dotti et al. ${ }^{32}, 11$ had a psychiatric disturbance (Table 2), of which 5 had behavioral changes, 4 had psychosis and 2 had depression. Thus, clearly, in this series the psychiatric manifestations were overrepresented, which is in contrast to the rarity of psychiatric signs in CTX. In the only published case series specifically focusing on the psychiatric spectrum of CTX, Berginer et al. ${ }^{20}$ reported four patients with disparate psychiatric syndromes. In this series, the first patient required numerous hospitalizations before and after the age of 32 years for irritability and personality changes with occasional hypersexuality and ended up with paranoid delusion and suicidal ideation at the age of 41 years. The second patient presented at the age of 37 years with atypical psychosis and paranoid delusion. The third patient suffered a severe catatonic episode at the age of 27 years and also had urinary-fecal incontinence. The last patient had been referred to a psychiatrist at the age of 22 years for aggressivity and agitation, and ultimately required many hospitalizations. In all patients of this series, however, the diagnosis of CTX had been easily made 10-15 years before the appearance of the psychiatric manifestations, as all four patients had had pes cavus and Achilles tendon xathomas since early or late adolescence, two out of four patients had learning difficulties and cognitive deterioration since childhood, and two out of four patients had bilateral cataracts. Importantly, by the time of the psychiatric evaluation, three out of four patients had already developed spastic paraparesis and cerebellar ataxia, that is, the disease had advanced enough to extensively involve the CNS.

Psychiatric manifestations and dementia in CTX are primarily the result of diffuse white matter pathology affecting multiple distributed intrahemispheric and interhemispheric neural networks. White matter pathology is caused by alterations of myelin lipid composition with markedly disproportional cholestanol incorporation into the glial cellular membranes, substitution of other sterols and extensive demyelination of white matter 


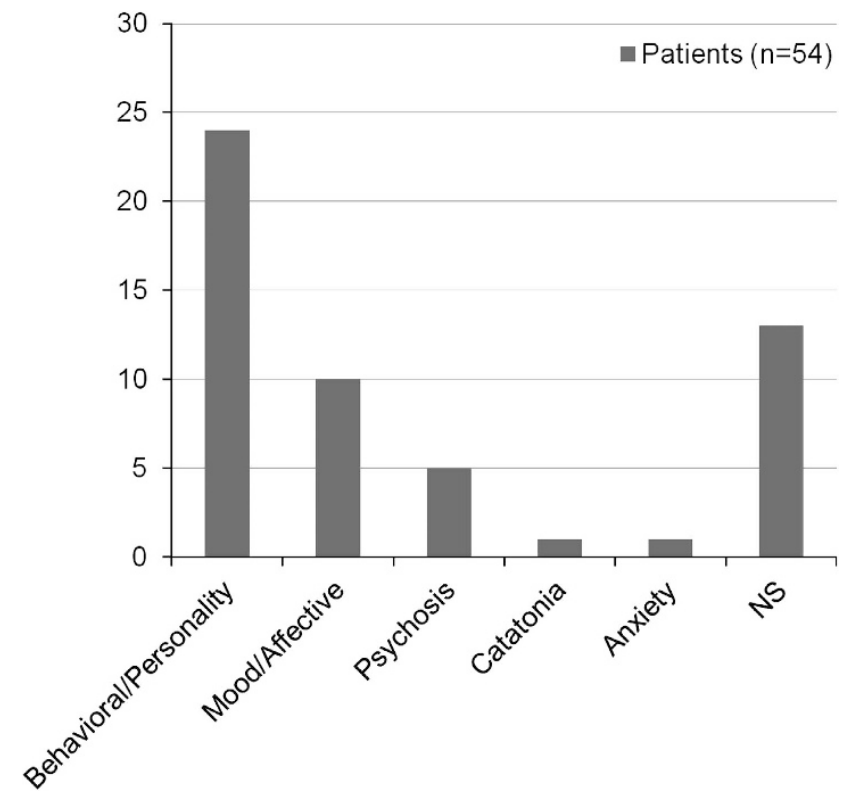

Figure 1. Different psychiatric manifestations related to cerebrotendinous xanthomatosis (CTX) and their frequency distribution. Patients with mood/affective disorders all suffered from depression, except for one patient who suffered from dysthymia. NS: not specified. Behavioral/personality and mood/affective disorders are clearly the predominant psychiatric manifestations in CTX (patients, $n=54)$.

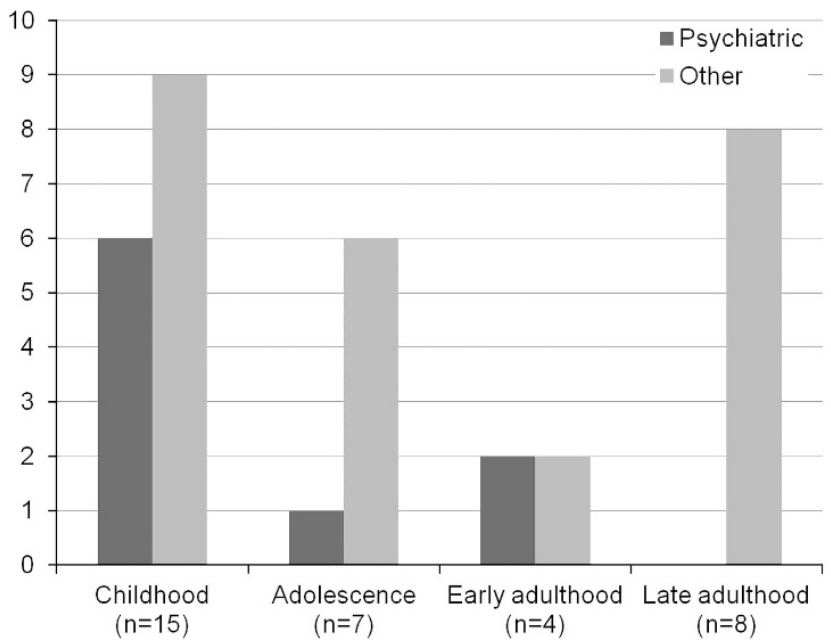

Figure 2. Incidence of disease presentation according to age group. Pure psyciatric and non-psychiatric presentation are plotted as bars of different color for the same age group. Pure psychiatric presentation of cerebrotendinous xanthomatosis (CTX) occurs most often in childhood (childhood: $\leqslant 12$ years; adolescence: 13 years $\leqslant$ age $\leqslant 18$ years; early adulthood: 19 years $\leqslant$ age $\leqslant 26$ years; late adulthood: age $>26$ years (patients, $n=34$ ).

tracts. ${ }^{53,54,56,57}$ However, alterations of the composition of the lipid bilayer of neuronal plasma membranes may also have repercussions in neuronal integrity and/or function at the level of soma, synapse or circuitry. ${ }^{41,44,45,53,79}$ Moreover, intracerebral lipid deposition in the form of xanthomas and local inflammatory reaction take their toll on myelinated axonal tracts, central grey matter formations and neuronal cell bodies. ${ }^{66-69}$ Thus, both demyelination and inevitable neuronal loss ultimately lead to the neurologic and complex psychiatric manifestations of CTX. This

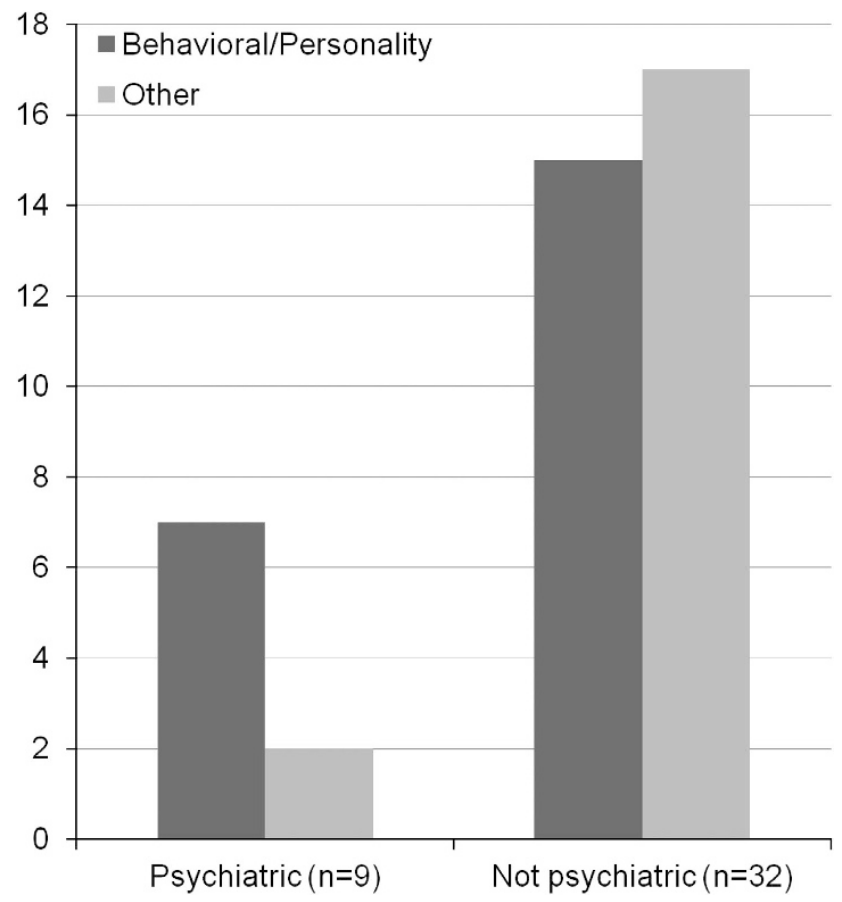

Figure 3. Frequency of behavioral/personality disorder in cerebrotendinous xanthomatosis (CTX) patients with pure psychiatric presentation as compared with patients with non-psychiatric presentation of CTX. Behavioral/personality disorder is the most frequent psychiatric manifestation in the group of CTX patients with pure psychiatric presentation $(n=9)$ of CTX, whereas it is as frequent as all the other psychiatric manifestations together in the group of CTX patients with non-psychiatric presentation $(n=32)$ of CTX (patients, $n=41$ ).

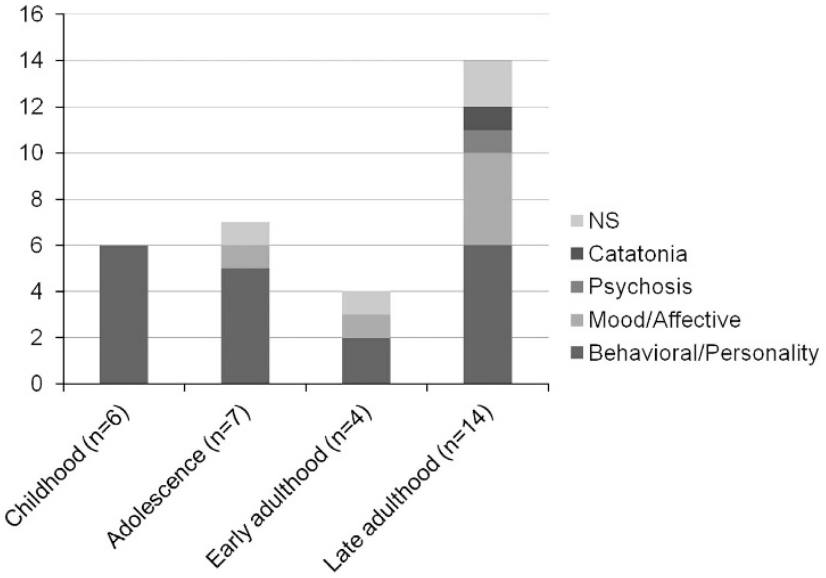

Figure 4. Distribution of cerebrotendinous xanthomatosis (CTX) patients with psychiatric manifestations according to age group and type of clinical psychopathology (childhood: $\leqslant 12$ years; adolescence: 13 years $\leqslant$ age $\leqslant 18$ years; early adulthood: 19 years $\leqslant$ age $\leqslant 26$ years; late adulthood: age $>26$ years (patients, $n=31$ ).

hypothesis is supported by anatomopathological findings, and both conventional and advanced neuroimaging. $3,4,13,28,41$, 44-46,53,79-81 Despite the definite organic etiopathogenesis of the neurobehavioral manifestations of CTX, depressive and anxiety symptoms, which constitute the second most common psychiatric manifestation in CTX, may sometimes be attributable in part to the physical and psychosocial impact of a chronic neurologic disease 
and cognitive decline on role functioning and quality of life, especially in younger patients without dementia. ${ }^{82}$

Multiple sclerosis (MS) is another CNS disease, where primarily white matter and secondarily grey matter are damaged in a random fashion, albeit by a different pathogenetic mechanism. MS may cause cognitive disturbance or dementia and, less often, organic psychopathology encompassing behavioural/personality disturbance, mood/affective disorders or psychosis. ${ }^{83-104}$ Psychiatric syndromes, such as bipolar disorders and atypical psychosis, often unassociated with cognitive disturbance or dementia, have been described, and euphoria sclerotica is a characteristic psychosyndrome in MS. ${ }^{83-85,89,91,94-96,99,104-108}$ Pure psychiatric presentation in MS is rare, as is the case for CTX. ${ }^{83,89,91,106,107}$ Major depressive disorder, which often is prodromal leading to diagnostic delay, is overrepresented in MS patients, as are suicidal ideation, anxiety and sleep disorders, and they are mainly believed to be secondary to physical illness and/or disease-modifying treatment. $84-87,90,93,95,96,98,99,102,104,107,108$ Athough in MS a detrimental autoimmune process is the culprit, and not an enzymatic metabolic defect as in CTX, the relative infrequence, variability and complexity of psychiatric signs in both these diseases can be explained by the stochasticity and widespread nature of neural tissue damage, and the prerequisite of a cumulative effect and critical burden of white/grey matter loss or dysfunction. ${ }^{85,86,90,103,104,106-113}$ Moreover, one can further classify the organic neuropsychiatric syndromes associated with CTX and MS, as primarily related to the integrity of subcortical myelinated systems, as is also reflected in similarities in their neuropsychological profiles with cognitive slowing, dysexecutive syndrome and attentional disorder. ${ }^{107-112}$ Indeed, the characteristics of dementia in the setting of CTX and MS merit their classification as white-matter dementias. ${ }^{109,112}$ Systematic advanced neuroimaging studies with positron emission tomography, single photon emission computerized tomography, magnetic resonance spectroscopy and diffusion tensor imaging are needed to clarify the importance of white matter functional, biochemical and microstructural abnormalities in the cognitive and neurobehavioral syndromes associated with CTX at various stages in the disease course, correlate these findings to neuropsychological assessment parameters and scores, as well as monitor the effects of disease-modifying treatment. ${ }^{41,79,80,113,114}$

Several other hereditary lipid storage disorders that cause leukoencepalopathy or leukodystrophy may result in or rarely present with complex organic neuropsychiatric phenotypes by affecting the cerebral white matter integrity and/or the neuronal elements and circuitry. ${ }^{108-144}$ In most lipid storage diseases of the nervous system (neurolipidoses) or leukodystrophies, which can present at some point with acute, progressive or relapsing psychosyndromes (Tay-Sachs and Sandhoff disease, Fabry disease, metachromatic leukodystrophy, adrenoleukodystrophy, Niemann-Pick type $C$, ceroid neuronal lipofuscinoses), pharmacotherapy of psychiatric manifestations has either poor effect or even worsens the condition, for example, as in adult-onset $\mathrm{GM}_{2}$ gangliosidoses, where phenothiazines and tricyclic antidepressants may have a detrimental effect by inhibiting the activity of lysosomal enzymes, thereby increasing lipid storage in neuronal cells. ${ }^{115-143}$ This is a little known domain of neuropsychiatry, because neurodegenerative/neurometabolic diseases are rare and seldom end up in the principal care of the psychiatrist. $8,115,117,134,142$ The latter happens when these conditions present either as complex neuropsychiatric syndromes or, more often, as cognitive/behavioral syndromes or learning difficulties in young age. ${ }^{8,115,117,119,120,122,125,127,131,133,134,142}$

Although psychiatric manifestations in CTX are not uncommon, psychiatric presentation in CTX is rare and, therefore, is the initial pharmacotherapy of CTX with psychoactive drugs. ${ }^{8}$ Our own clinical experience from the CTX patients evaluated at the La Salpêtrière University Hospital is that pharmacotherapy (anxiolytic, antidepressive or antipsychotic treatments) and psychotherapy (cognitive-behavioral treatments) have little or only temporary effects in CTX-related organic psychosyndromes without improving prognosis, both in patients with advanced disease and dementia, and also in younger patients with mild cognitive disturbance. However, if psychiatric symptomatology is compounded by secondary depression or anxiety disorder in CTX, it may be partially amenable to symptomatic pharmacotherapy with antidepressants or anxiolytics, such as selective serotonin reuptake inhibitors, and a treatment trial in a CTX patient with mild or major depressive or anxiety disorder is anavoidable, as it is warranted. ${ }^{82}$ However, specific disease-modifying treatment with CDCA has the potential to both alleviate symptomatology and improve prognosis by slowing down neurodegeneration and disease progression, thus preventing or even reversing psychiatric manifestations. ${ }^{8}$ This is all the more important for the young undiagnosed patient with CTX that presents to the child and adolescent psychiatry department, with an elusive psychosyndrome that is slowly but steadily progressive and is often associated with cognitive disturbance. ${ }^{8,144}$ Therefore, timely diagnosis and specific treatment is the ultimate goal in the management of neuropsychiatric manifestations of CTX.

In conclusion, psychiatric manifestations in CTX are variable, encompassing personality, affective and psychotic disorders, and either appear late in the course of the disease in the context of an organic dementia complicating a chronic neurologic tableau of spastic paraparesis and the cerebellar or early in the course of the illness preceded by cognitive disturbance. Chronic diarrheas, tendon xanthomas and cataracts are salient early features of this systemic illness that herald the neurological or psychiatric signs and should raise the diagnostician's index of suspicion. ${ }^{145-148}$ The earlier the onset of psychiatric symptoms, the milder is their severity, with personality/behavioral disorder, irritability and aggressivity most prominent in the 'younger than $25^{\prime}$ age group. Irritability, aggressivity, attention-deficit hyperactivity disorder and oppositional-defiant disorder in childhood or adolescence, which easily can be disregarded or misdiagnosed as 'travails of youth' or 'peer-group influence', should therefore prompt a thorough neurologic evaluation with a complete physical and ophthalmologic check-up, especially in a background of consanguinity that increases the probability for autosomal recessive inherited disorders. ${ }^{144}$ The attending psychiatrist should be aware of CTX, its psychiatric manifestations and its characteristic physical signs, and strive to exclude it, especially as anecdotal reports have shown a beneficial effect of timely CDCA treatment on psychiatric symptoms and overall prognosis. ${ }^{8,145-148}$ We hope that this review will raise awareness of this devastating but treatable neuropsychiatric inherited disorder among psychiatrists.

\section{CONFLICT OF INTEREST}

The author declares no conflict of interest.

\section{REFERENCES}

1 Harris Jr WR. Cerebrotendinous xanthomatosis. N Engl J Med 1968; 278: 857.

2 Berginer VM, Salen G, Shefer S. Cerebrotendinous xanthomatosis. Neurol Clin 1989; 7: 55-74.

3 Moghadasian MH, Salen G, Frohlich JJ, Scudamore CH. Cerebrotendinous xanthomatosis: a rare disease with diverse manifestations. Arch Neurol 2002; 59: 527-529.

4 Moghadasian $\mathrm{MH}$. Cerebrotendinous xanthomatosis: clinical course, genotypes and metabolic backgrounds. Clin Invest Med 2004; 27: 42-50.

5 Salen G, Shefer S, Berginer V. Biochemical abnormalities in cerebrotendinous xanthomatosis. Dev Neurosci 1991; 13: 363-370.

6 Leitersdorf E, Meiner V. Cerebrotendinous xanthomatosis. Curr Opin Lipidol 1994; 5: $138-142$. 
7 Mondelli M, Sicurelli F, Scarpini C, Dotti MT, Federico A. Cerebrotendinous xanthomatosis: 11-year treatment with chenodeoxycholic acid in five patients. An electrophysiological study. J Neurol Sci 2001; 190: 29-33.

8 Bonnot O, Fraidakis MJ, Lucanto R, Chauvin D, Kelley N, Plaza M et al. Cerebrotendinous xanthomatosis presenting with severe externalized disorder: improvement after one year of treatment with chenodeoxycholic acid. CNS Spectr 2010; 15: 231-236.

9 Verrips A, Wevers RA, Van Engelen BG, Keyser A, Wolthers BG, Barkhof F et al. Effect of simvastatin in addition to chenodeoxycholic acid in patients with cerebrotendinous xanthomatosis. Metabolism 1999; 48: 233-238.

10 Lorincz MT, Rainier S, Thomas D, Fink JK. Cerebrotendinous xanthomatosis: possible higher prevalence than previously recognized. Arch Neurol 2005; 62: 1459-1463.

11 Reshef A, Meiner V, Berginer VM, Leitersdorf E. Molecular genetics of cerebrotendinous xanthomatosis in Jews of north African origin. J Lipid Res 1994; 35 478-483.

12 Cruysberg JR. Cerebrotendinous xanthomatosis: juvenile cataract and chronic diarrhea before the onset of neurologic disease. Arch Neurol 2002; 59: 527529.

13 Waterreus RJ, Koopman BJ, Wolthers BG, Oosterhuis HJ. Cerebrotendinous xanthomatosis (CTX): a clinical survey of the patient population in The Netherlands. Clin Neurol Neurosurg 1987; 89: 169-175.

14 Grandas F, Martín-Moro M, Garcia-Muñozguren S, Anaya F. Early-onset parkinsonism in cerebrotendinous xanthomatosis. Mov Disord 2002; 17: 13961397.

15 Gilad R, Lampl Y, Lev D, Sadeh M. Cerebrotendinous xanthomatosis without xanthomas. Clin Genet 1999; 56: 405-406.

16 Fleischmajer R, Tint GS, Bennett HD. Normolipemic tendon and tuberous xanthomas. J Am Acad Dermatol 1981; 5: 290-296.

17 Chen PS, Fleck RP, Calisi CM, Kozina JA, Feld GK. Macroreentrant ventricular tachycardia and coronary artery disease in cerebrotendinous xanthomatosis. Am J Cardiol 1989; 64: 680-682.

18 Kawabata M, Kuriyama M, Mori S, Sakashita I, Osame M. Pulmonary manifestations in cerebrotendinous xanthomatosis. Intern Med 1998; 37: 901-902.

19 Berginer VM, Shany S, Alkalay D, Berginer J, Dekel S, Salen G et al. Osteoporosis and increased bone fractures in cerebrotendinous xanthomatosis. Metabolism 1993; 42: 1497-1498.

20 Berginer VM, Foster NL, Sadowsky M, Townsend 3rd JA, Siegel GJ, Salen G. Psychiatric disorders in patients with cerebrotendinous xanthomatosis. $\mathrm{Am} J$ Psychiatry 1988; 145: 354-357.

21 Lee Y, Lin PY, Chiu NM, Chang WN, Wen JK. Cerebrotendinous xanthomatosis with psychiatric disorders: report of three siblings and literature review. Chang Gung Med J 2002; 25: 334-340.

22 Price Evans DA, Salah KA, Mobrad MA, Mitchell WD, Olin M, Eggertsen G. Cerebrotendinous xanthomatosis in a Saudi Arabian family-genotyping and longterm follow-up. Saudi Med J 2007; 28: 1113-1118.

23 Philippart M, Van Bogaert L. Cholestanolosis (cerebrotendinous xanthomatosis). A follow-up study on the original family. Arch Neurol 1969; 21: 603-610.

24 Shapiro S. Depression in a patient with dementia secondary to cerebrotendinous xanthomatosis. J Nerv Ment Dis 1983; 171: 568-571.

25 Burnstein M, Buckwalter KA, Martel W, McClatchey KD, Quint D. Case report: Cerebrotendinous xanthomatosis. Skeletal Radiol 1987; 16: 346-349.

26 Laurent A, Dairou F, Luc G, Truffert J, Lapresle J, de Gennes JL. [Van Bogaert's cerebrotendinous xanthomatosis. A study of 3 cases]. Ann Med Interne (Paris) 1988; 139: 395-402(in French).

27 Wevers RA, Cruysberg JR, Van Heijst AF, Janssen-Zijlstra FS, Renier WO, Van Engelen BG et al. Paediatric cerebrotendinous xanthomatosis. J Inherit Metab Dis 1992; 15: 374-376.

28 Soffer D, Benharroch D, Berginer V. The neuropathology of cerebrotendinous xanthomatosis revisited: a case report and review of the literature. Acta Neuropathol 1995; 90: 213-220.

29 Verrips A, Steenbergen-Spanjers GC, Luyten JA, van den Heuvel LP, Keyser A, Gabreëls FJ et al. Two new mutations in the sterol 27-hydroxylase gene in two families lead to cerebrotendinous xanthomatosis. Hum Genet 1996; 98: 735-737.

30 Sperhake JP, Matschke J, Orth U, Gal A, Püschel K. Sudden death due to cerebrotendinous xanthomatosis confirmed by mutation analysis. Int $J$ Legal Med 2000; 113: 110-113.

31 Sugama S, Kimura A, Chen W, Kubota S, Seyama Y, Taira N et al. Frontal lobe dementia with abnormal cholesterol metabolism and heterozygous mutation in sterol 27-hydroxylase gene (CYP27). J Inherit Metab Dis 2001; 24: 379-392.

32 Dotti MT, Rufa A, Federico A. Cerebrotendinous xanthomatosis: heterogeneity of clinical phenotype with evidence of previously undescribed ophthalmological findings. J Inherit Metab Dis 2001; 24: 696-706.

33 Bartholdi D, Zumsteg D, Verrips A, Wevers RA, Sistermans E, Hess K et al. Spinal phenotype of cerebrotendinous xanthomatosis--a pitfall in the diagnosis of multiple sclerosis. J Neurol 2004; 251: 105-107.
34 Guyant-Marechal L, Verrips A, Girard C, Wevers RA, Zijlstra F, Sistermans E et al. Unusual cerebrotendinous xanthomatosis with fronto-temporal dementia phenotype. Am J Med Genet A 2005; 139: 114-117.

35 Siman-Tov T, Meiner V, Gadoth N. Could steroids mask the diagnosis of cerebrotendinous xanthomatosis? J Neurol Sci 2006; 243: 83-86.

36 Gonzalez-Cuyar LF, Hunter B, Harris PL, Perry G, Smith MA, Castellani RJ. Cerebrotendinous xanthomatosis: case report with evidence of oxidative stress. Redox Rep 2007; 12: 119-124.

37 Pilo de la Fuente B, Ruiz I, Lopez de Munain A, Jimenez-Escrig A. Cerebrotendinous xanthomatosis: neuropathological findings. J Neurol 2008; 255: 839-842.

38 Szlago M, Gallus GN, Schenone A, Patiño ME, Sfaelo Z, Rufa A et al. The first cerebrotendinous xanthomatosis family from Argentina: a new mutation in CYP27A1 gene. Neurology 2008; 70: 402-404.

39 Zacherl M, Sourij H, Beham A, Emberger W, Leithner A, Windhager W. [Cerebrotendinous xanthomatosis. Hereditary lipid storage disease leading to bilateral swelling of Achilles tendon]. Orthopade 2008; 37: 704-708(in German).

40 Filippi J, Irarrázaval S, Peredo P, Mellado P. [Cerebrotendinous xanthomatosis: report of one case]. Rev Med Chil 2009; 137: 815-820(in Spanish).

41 Chang CC, Lui CC, Wang JJ, Huang SH, Lu CH, Chen C et al. Multi-parametric neuroimaging evaluation of cerebrotendinous xanthomatosis and its correlation with neuropsychological presentations. BMC Neurol 2010; 10: 59.

42 Pilo de la Fuente B, Sobrido MJ, Girós M, Pozo L, Lustres M, Barrero F et al. [Usefulness of cholestanol levels in the diagnosis and follow-up of patients with cerebrotendinous xanthomatosis]. Neurologia 2011a; 26: 397-404(in Spanish).

43 Pilo-de-la-Fuente B, Jimenez-Escrig A, Lorenzo JR, Pardo J, Arias M, Ares-Luque A et al. Cerebrotendinous xanthomatosis in Spain: clinical, prognostic, and genetic survey. Eur J Neurol 2011b; 18: 1203-1211.

44 Barkhof F, Verrips A, Wesseling P, van Der Knaap MS, van Engelen BG, Gabreels FJ et al. Cerebrotendinous xanthomatosis: the spectrum of imaging findings and the correlation with neuropathologic findings. Radiology 2000; 217: 869-876.

45 Vanrietvelde F, Lemmerling M, Mespreuve M, Crevits L, De Reuck J, Kunnen M. MRI of the brain in cerebrotendinous xanthomatosis. Eur Radiol 2000; 10: $576-578$.

46 De Stefano N, Dotti MT, Mortilla M, Federico A. Magnetic resonance imaging and spectroscopic changes in brains of patients with cerebrotendinous xanthomatosis. Brain 2001; 124: 121-131.

47 van Bogaert L, Scherer HJ, Epstein E A. Cerebral Form of Generalized Cholesterinose [in French]. Masson et Cie: Paris, France, 1937.

48 van Bogaert L, Scherer HJ, Froelich A, Epstein E. Une deuxieme observation de cholesterinose tendineuse symetrique avec symptomes cerebraux. Ann Med 1937; 42: 69.

49 Dubois B, Slachevsky A, Litvan I, Pillon B. The FAB: a Frontal Assessment Battery at bedside. Neurology 2000; 55: 1621-1626.

50 Slachevsky A, Villalpando JM, Sarazin M, Hahn-Barma V, Pillon B, Dubois B. Frontal assessment battery and differential diagnosis of frontotemporal dementia and Alzheimer disease. Arch Neurol 2004; 61: 1104-1107.

51 Menkes JH, Schimschock JR, Swanson PD. Cerebrotendinous xanthomatosis: the storage of cholestanol within the nervous system. Arch Neurol 1968; 19: 47-53.

52 Salen G, Berginer V, Shore V, Horak I, Horak E, Tint GS et al. Increased concentrations of cholestanol and apolipoprotein $B$ in cerebrospinal fluid of patients with cerebrotendinous xanthomatosis: effect of chenodeoxycholic acid. $N$ Engl J Med 1987; 316: 1233-1238.

53 Dotti MT, Federico A, Signorini E, Caputo N, Venturi C, Filosomi G et al. Cerebrotendinous xanthomatosis (van Bogaert-Scherer-Epstein disease): CT and MR findings. Am J Neuroradiol 1994; 15: 1721-1726.

54 Benarroch EE. Brain cholesterol metabolism and neurologic disease. Neurology 2008; 71: 1368-1373.

55 Oftebro H, Björkhem I, Skrede S, Schreiner A, Pederson Jl. Cerebrotendinous xanthomatosis: a defect in mitochondrial 26-hydroxylation required for normal biosynthesis of cholic acid. J Clin Invest 1980; 65: 1418-1430.

56 Bhattacharyya AK, Lin DS, Connor WE. Cholestanol metabolism in patients with cerebrotendinous xanthomatosis: absorption, turnover, and tissue deposition. J Lipid Res 2007; 48: 185-192.

57 Panzenboeck U, Andersson U, Hansson M, Sattler W, Meaney S, Bjorkhem I. On the mechanism of cerebral accumulation of cholestanol in patients with cerebrotendinous xanthomatosis. J Lipid Res 2007; 48: 1167-1174.

58 Cali JJ, Hsieh CL, Francke U, Russell DW. Mutations in the bile acid biosynthetic enzyme sterol 27-hydroxylase underlie cerebrotendinous xanthomatosis. J Biol Chem 1991; 266: 7779-7783.

59 Meiner V, Meiner Z, Reshef A, Bjorkhem I, Leitersdorf E. Cerebrotendinous xanthomatosis: molecular diagnosis enables presymptomatic detection of a treatable disease. Neurology 1994; 44: 288-290. 
60 Lee MH, Hazard S, Carpten JD, Yi S, Cohen J, Gerhardt GT et al. Fine-mapping, mutation analyses, and structural mapping of cerebrotendinous xanthomatosis in U.S. pedigrees. J Lipid Res 2001; 42: 159-169.

61 Clayton PT, Verrips A, Sistermans E, Mann A, Mieli-Vergani G, Wevers R. Mutations in the sterol 27-hydroxylase gene (CYP27A) cause hepatitis of infancy as well as cerebrotendinous xanthomatosis. J Inherit Metab Dis 2002; 25: 501-513.

62 Von Bahr S, Björkhem I, Van't Hooft F, Alvelius G, Nemeth A, Sjövall J et al. Mutation in the sterol 27-hydroxylase gene associated with fatal cholestasis in infancy. J Pediatr Gastroenterol Nutr 2005; 40: 481-486.

63 Gallus GN, Dotti MT, Federico A. Clinical and molecular diagnosis of cerebrotendinous xanthomatosis with a review of the mutations in the CYP27A1 gene. Neurol Sci 2006; 27: 143-149.

64 Federico A, Dotti MT, Loré F, Nuti R. Cerebrotendinous xanthomatosis: pathophysiological study on bone metabolism. J Neurol Sci 1993; 115: 67-70.

65 Dotti MT, Mondillo S, Plewnia K, Agricola E, Federico A. Cerebrotendinous xanthomatosis: evidence of lipomatous hypertrophy of the atrial septum. J Neurol 1998; 245: 723-6.

66 Verrips A, Nijeholt GJ, Barkhof F, Van Engelen BG, Wesseling P, Luyten JA et al. Spinal xanthomatosis: a variant of cerebrotendinous xanthomatosis. Brain 1999; 122: 1589-1595.

67 Verrips A, Hoefsloot LH, Steenbergen GC, Theelen JP, Wevers RA, Gabreëls FJ et al. Clinical and molecular genetic characteristics of patients with cerebrotendinous xanthomatosis. Brain 2000; 123: 908-19.

68 Dotti MT, Federico A, Garuti R, Calandra S. Cerebrotendinous xanthomatosis with predominant parkinsonian syndrome: further confirmation of the clinical heterogeneity. Mov Disord 2000; 15: 1017-9.

69 Ohno T, Kobayashi S, Hayashi M, Sakurai M, Kanazawa I. Diphenylpyralineresponsive parkinsonism in cerebrotendinous xanthomatosis: long-term follow up of three patients. J Neurol Sci 2001; 182: 95-7.

70 Salen G, Meriwether TW, Nicolau G. Chenodesoxycholic acid inhibits increased cholesterol and cholestanol synthesis in patients with cerebrotendinous xanthomatosis. Biochem Med 1975; 14: 57-74.

71 Berginer VM, Salen G, Shefer S. Long-term treatment of cerebrotendinous xanthomatosis with chenodeoxycholic acid. N Engl J Med 1984; 311: 1649-1652.

72 Dotti MT, Lütjohann D, von Bergmann K, Federico A. Normalisation of serum cholestanol concentration in a patient with cerebrotendinous xanthomatosis by combined treatment with chenodeoxycholic acid, simvastatin and LDL apheresis. Neurol Sci 2004; 25: 185-191.

73 Donaghy M, King RH, McKeran RO, Schwartz MS, Thomas PK. Cerebrotendinous xanthomatosis: clinical, electrophysiological and nerve biopsy findings, and response to treatment with chenodeoxycholic acid. J Neurol 1990; 237: 216-219.

74 Mondelli M, Rossi A, Scarpini C, Dotti MT, Federico A. Evoked potentials in cerebrotendinous xanthomatosis and effect induced by chenodeoxycholic acid. Arch Neurol 1992; 49: 469-475.

75 Restuccia D, Di Lazzaro V, Servidei S, Colosimo C, Tonali P. Somatosensory and motor evoked potentials in the assessment of cerebrotendinous xanthomatosis before and after treatment with chenodeoxycholic acid: a preliminary study. J Neurol Sci 1992; 112: 139-146.

76 Tokimura Y, Kuriyama M, Arimura K, Fujiyama J, Osame M. Electrophysiological studies in cerebrotendinous xanthomatosis. J Neurol Neurosurg Psychiatry 1992 55: 52-55.

77 Van Heijst AF, Verrips A, Wevers RA, Cruysberg JR, Renier WO, Tolboom J. Treatment and follow-up of children with cerebrotendinous xanthomatosis. Eur $J$ Pediatr 1998; 157: 313-316.

78 Burnett JR, Moses EA, Croft KD, Brown AJ, Grainger K, Vasikaran SD et al. Clinical and biochemical features, molecular diagnosis and long-term management of a case of cerebrotendinous xanthomatosis. Clin Chim Acta 2001; 306: 63-69.

79 Selva-O'Callaghan A, Bardes I, Jacas C, Jubany L, Lorenzo-Bosquet C, CuberasBorrós $\mathrm{G}$ et al. SPECT imaging for brain improvement quantification in a patient with cerebrotendinous xanthomatosis. Clin Nucl Med 2011; 36: 38-39.

80 Berginer VM, Berginer J, Korczyn AD, Tadmor R. Magnetic resonance imaging in cerebrotendinous xanthomatosis: a prospective clinical and neuroradiological study. J Neurol Sci 1994; 122: 102-108.

81 Chakraverty S, Griffiths PD, Walls TJ, McAllister VL. Cerebrotendinous xanthomatosis in two sisters: case reports and MR imaging. Clin Radiol 1995; 50: 117-119.

82 Chen Q, Liu W, Jiang B, Yu R, Li X, Li H. Fluoxetine-responsive depression in a Chinese cerebrotendinous xanthomatosis. Gen Hosp Psychiatry 2012; 34: 578.

83 Fontaine B, Seilhean D, Tourbah A, Daumas-Duport C, Duyckaerts C, Benoit N et al. Dementia in two histologically confirmed cases of multiple sclerosis: one case with isolated dementia and one case associated with psychiatric symptoms. J Neurol Neurosurg Psychiatry 1994; 57: 353-359.

84 Fragoso YD, Frota ER, Lopes JS, Noal JS, Giacomo MC, Gomes S et al. Severe depression, suicide attempts, and ideation during the use of interferon beta by patients with multiple sclerosis. Clin Neuropharmacol 2010; 33: 312-316.
85 Feinstein A. Multiple sclerosis and depression. Mult Scler 2011; 17: 1276-1281. 86 Vattakatuchery JJ, Rickards H, Cavanna AE. Pathogenic mechanisms of depression in multiple sclerosis. J Neuropsychiatry Clin Neurosci 2011; 23: 261-276.

87 Göksel Karatepe A, Kaya T, Günaydn R, Demirhan A, Ce P, Gedizlioğlu M. Quality of life in patients with multiple sclerosis: the impact of depression, fatigue, and disability. Int J Rehabil Res 2011; 34: 290-298.

88 Lauterbach EC, Mendez MF. Psychopharmacological neuroprotection in neurodegenerative diseases, part III: criteria-based assessment: a report of the ANPA committee on research. I Neuropsychiatry Clin Neurosci 2011; 23: 242-260.

89 Aggarwal A, Sharma D, Kumar R, Sharma R. Acute psychosis as the initial presentation of MS: A case report. Int MS J 2011; 17: 54-57.

90 Byatt N, Rothschild AJ, Riskind P, lonete C, Hunt AT. Relationships between multiple sclerosis and depression. J Neuropsychiatry Clin Neurosci 2011; 23: 198-200.

91 Carrieri PB, Montella S, Petracca M. Psychiatric onset of multiple sclerosis: description of two cases. J Neuropsychiatry Clin Neurosci 2011; 23: E6.

92 Sayao AL, Bueno AM, Devonshire V, Tremlett H, Hashimoto S, Oger J et al. The psychosocial and cognitive impact of longstanding 'benign' multiple sclerosis. Mult Scler 2011; 17: 1375-1383.

93 Price A, Rayner L, Okon-Rocha E, Evans A, Valsraj K, Higginson IJ et al. Antidepressants for the treatment of depression in neurological disorders: a systematic review and meta-analysis of randomised controlled trials. J Neurol Neurosurg Psychiatry 2011; 82: 914-923.

94 lacovides A, Andreoulakis E. Bipolar disorder and resembling special psychopathological manifestations in multiple sclerosis: a review. Curr Opin Psychiatry 2011; 24: 336-340.

95 Stenager EN, Jensen B, Stenager M, Stenager K, Stenager E. Suicide attempts in multiple sclerosis. Mult Scler 2011; 17: 1265-1268.

96 Bruce JM, Lynch SG. Personality traits in multiple sclerosis: association with mood and anxiety disorders. J Psychosom Res 2011; 70: 479-485.

97 Baumstarck-Barrau K, Simeoni MC, Reuter F, Klemina I, Aghababian V, Pelletier J et al. Cognitive function and quality of life in multiple sclerosis patients: a crosssectional study. BMC Neurol 2011; 11: 17

98 Barwick FH, Arnett PA. Relationship between global cognitive decline and depressive symptoms in multiple sclerosis. Clin Neuropsychol 2011; 25: 193-209.

99 Gaskill A, Foley FW, Kolzet J, Picone MA. Suicidal thinking in multiple sclerosis. Disabil Rehabil 2011; 33: 1528-1536.

100 Goretti B, Portaccio E, Ghezzi A, Lori S, Moiola L, Falautano M et al. Multiple Sclerosis Study Group of the Italian Neurological Society. Fatigue and its relationships with cognitive functioning and depression in paediatric multiple sclerosis. Mult Scler 2012; 18: 329-334.

101 Giordano A, Ferrari G, Radice D, Randi G, Bisanti L, Solari A. POSMOS study. Health-related quality of life and depressive symptoms in significant others of people with multiple sclerosis: a community study. Eur J Neurol 2012; 19: 847-854.

102 Holmes JM, Ford E, Yuill F, Drummond AE, Lincoln NB. Attendance at a psychological support group for people with multiple sclerosis and low mood. Disabil Rehabil 2012; 34: 1323-1327.

103 Sisterolli-Diniz D, Oliveira Ad, Paula DS, Rodrigues RV, Silva NA. Functional impairments in white matter syndrome of neuropsychiatric systemic lupus erythematosus are similar to those observed in patients with multiple sclerosis. Arq Neuropsiquiatr 2012; 70: 769-773.

104 Curral R, Correia R, Lopes R, Maia D, Rio E, Bastos-Leite AJ. Dementia in multiple sclerosis: report of a case with cortical gray matter involvement and frontotemporal-like clinical features. Psychiatry Res 2012; 202: 172-174.

105 Moss-Morris R, Dennison L, Landau S, Yardley L, Silber E, Chalder T. A randomized controlled trial of cognitive behavioral therapy (CBT) for adjusting to multiple sclerosis (the saMS trial): Does CBT work and for whom does it work? J Consult Clin Psychol 2013; 81: 251-262.

106 Sarısoy G, Terzi M, Gümüş K, Pazvantoğlu O. Psychiatric symptoms in patients with multiple sclerosis. Gen Hosp Psychiatry 2013; 35: 134-140.

107 Guernion N, Le Cadet E, Tirel A, Le Galudec M, Edan G, Walter M. [Neuropsychiatric manifestations in multiple sclerosis (MS): Might psychotic symptoms signal the onset of the disease?]. Presse Med 2013, (in French).

108 Zasler ND, Martelli MF, Jacobs HE. Neurobehavioral disorders. Handb Clin Neurol 2013; 110: 377-388

109 Filley CM. The frontal lobes. Handb Clin Neurol 2010; 95: 557-570.

110 Filley CM. White matter: organization and functional relevance. Neuropsychol Rev 2010; 20: 158-173.

111 Filley CM. White matter: beyond focal disconnection. Neurol Clin 2011; 29: 81-97.

112 Filley CM. White matter dementia. Ther Adv Neurol Disord 2012; 5: 267-277.

113 Filley CM. Exploring white matter microstructure: new insights from diffusion tensor imaging. Neurology 2009; 73: 1718-1719. 
114 Gropman AL. Expanding the diagnostic and research toolbox for inborn errors of metabolism: the role of magnetic resonance spectroscopy. Mol Genet Metab 2005; 86: 2-9.

115 Lejoyeux M, Dubois G, Turpin JC, Baumann N, Lempérière T. Arylsulfatase A activity among psychotic patients. Psychiatry Res 1989; 30: 107-108 1989.

116 Lyon-Caen O, Benoit N, Carreau V, Montreuil M, Menage P, Lubetzki C et al. Cognitive function in adult adrenoleukodystrophy: comparison with leukoaraiosis and multiple sclerosis. Dev Neurosci 1991; 13: 251-253.

117 Shulman LM, David NJ, Weiner WJ. Psychosis as the initial manifestation of adultonset Niemann-Pick disease type C. Neurology 1995; 45: 1739-1743.

118 Simon DK, Rodriguez ML, Frosch MP, Quackenbush EJ, Feske SK, Natowicz MR. A unique familial leukodystrophy with adult onset dementia and abnormal glycolipid storage: a new lysosomal disease. J Neurol Neurosurg Psychiatry 1998; 65: 251-254.

119 Baumann N, Turpin JC. Adult-onset leukodystrophies. J Neurol 2000; 247: 751759.

120 Baumann N, Turpin JC, Lefevre M, Colsch B. Motor and psycho-cognitive clinical types in adult metachromatic leukodystrophy: genotype/phenotype relationships? J Physiol (Paris) 2002; 96: 301-306.

121 Baumann N, Turpin JC, Lefevre M, Colsch B. [Degenerative neurological diseases of the central nervous system related to genetic neurolipidoses]. Bull Acad Natl Med 2003; 187: 141-151(in French).

122 Turpin JC, Baumann N. [Presenting psychiatric and cognitive disorders in adult neurolipidoses]. Rev Neurol (Paris) 2003; 159: 637-647(in French).

123 Sedel F, Tourbah A, Baumann N, Fontaine B, Aubourg P, Lubetzki C et al. [Adult onset hereditary leukoencephalopathies]. Rev Neurol (Paris) 2005; 161: 916-931(in French).

124 Saudubray JM, Sedel F, Walter JH. Clinical approach to treatable inborn metabolic diseases: an introduction. J Inherit Metab Dis 2006; 29: 261-274.

125 Walterfang M, Fietz M, Fahey M, Sullivan D, Leane P, Lubman DI et al. The neuropsychiatry of Niemann-Pick type $C$ disease in adulthood. $J$ Neuropsychiatry Clin Neurosci 2006; 18: 158-170.

126 Sedel F, Turpin JC, Baumann N. [Neurological presentations of lysosomal diseases in adult patients]. Rev Neurol (Paris) 2007; 163: 919-929(in French).

127 Sedel F, Baumann N, Turpin JC, Lyon-Caen O, Saudubray JM, Cohen D. Psychiatric manifestations revealing inborn errors of metabolism in adolescents and adults. J Inherit Metab Dis 2007; 30: 631-641.

128 Sévin M, Lesca G, Baumann N, Millat G, Lyon-Caen O, Vanier MT et al. The adult form of Niemann-Pick disease type C. Brain 2007; 130: 120-133.

129 Sedel F, Turpin JC, Baumann N. [Neurological presentations of lysosomal diseases in adult patients]. Rev Neurol (Paris) 2007; 163: 919-929.

130 Sedel F, Lyon-Caen O, Saudubray JM. [Treatable hereditary neurometabolic diseases]. Rev Neurol (Paris) 2007; 163: 884-896(in French).

131 Sedel F, Baumann N, Turpin JC, Lyon-Caen O, Saudubray JM, Cohen D. Psychiatric manifestations revealing inborn errors of metabolism in adolescents and adults. J Inherit Metab Dis 2007; 30: 631-641.

132 Sedel F, Lyon-Caen O, Saudubray JM. Therapy insight: inborn errors of metabolism in adult neurology-a clinical approach focused on treatable diseases. Nat Clin Pract Neurol 2007; 3: 279-290.
133 Klarner B, Klünemann HH, Lurding R, Aslanidis C, Rupprecht R. Neuropsychological profile of adult patients with Niemann-Pick C1 (NPC1) mutations. J Inherit Metab Dis 2007; 30: 60-67.

134 Lahutte B, Cornic F, Bonnot O, Consoli A, An-Gourfinkel I, Amoura Z et al. Multidisciplinary approach of organic catatonia in children and adolescents may improve treatment decision making. Prog Neuropsychopharmacol Biol Psychiatry 2008; 32: 1393-1398.

135 Sedel F, Tourbah A, Fontaine B, Lubetzki C, Baumann N, Saudubray JM et al Leukoencephalopathies associated with inborn errors of metabolism in adults. J Inherit Metab Dis 2008; 31: 295-307.

136 Sedel F, Tourbah A, Fontaine B, Lubetzki C, Baumann N, Saudubray JM et al. Leukoencephalopathies associated with inborn errors of metabolism in adults. J Inherit Metab Dis 2008; 31: 295-307.

137 Sedel F, Saudubray JM, Roze E, Agid Y, Vidailhet M. Movement disorders and inborn errors of metabolism in adults: a diagnostic approach. $J$ Inherit Metab Dis 2008; 31: 308-318.

138 Sedel F, Saudubray JM, Roze E, Agid Y, Vidailhet M. Movement disorders and inborn errors of metabolism in adults: a diagnostic approach. $J$ Inherit Metab Dis 2008; 31: 308-318.

139 Hannequin D, Guyant-Maréchal L, Le Ber I, Wallon D, Campion D, Sedel F. [Insanity in the young: diagnostic course]. Rev Neurol (Paris) 2009; 165: Spec No 2 F87-F96(in French).

140 Wraith JE, Imrie J. New therapies in the management of Niemann-Pick type C disease: clinical utility of miglustat. Ther Clin Risk Manag 2009; 5: 877-887.

141 Wraith JE, Guffon N, Rohrbach M, Hwu WL, Korenke GC, Bembi B et al. Natural history of Niemann-Pick disease type $\mathrm{C}$ in a multicentre observational retrospective cohort study. Mol Genet Metab 2009; 98: 250-254.

142 Klünemann $\mathrm{HH}$, Santosh PJ, Sedel F. Treatable metabolic psychoses that go undetected: what Niemann-Pick type $C$ can teach us. Int J Psychiatry Clin Pract 2012; 16: 162-169.

143 Sedel F. [Inborn errors of metabolism in adult neurology]. Rev Neurol (Paris) 2013; 169(Suppl 1): S63-S69(in French).

144 Enns GM, Packman W. The adolescent with an inborn error of metabolism: medical issues and transition to adulthood. Adolesc Med 2002; 13: 315-329.

145 Federico A, Dotti MT. Cerebrotendinous xanthomatosis: clinical manifestations, diagnostic criteria, pathogenesis, and therapy. J Child Neurol 2003; 18: 633-638.

146 Berginer VM, Gross B, Morad K, Kfir N, Morkos S, Aaref S et al. Chronic diarrhea and juvenile cataracts: think cerebrotendinous xanthomatosis and treat. Pediatrics 2009; 123: 143-147.

147 Cruysberg JR, Wevers RA, Tolboom JJ. Juvenile cataract associated with chronic diarrhea in pediatric cerebrotendinous xanthomatosis. Am J Ophthalmol 1991; 112: 606-607.

148 Verrips A, van Engelen BG, Wevers RA, van Geel BM, Cruysberg JR, van den Heuvel LP et al. Presence of diarrhea and absence of tendon xanthomas in patients with cerebrotendinous xanthomatosis. Arch Neurol 2000; 57: 520-524.

(c) (i) $\Theta$ This work is licensed under a Creative Commons AttributionConCommercial-NoDerivs 3.0 Unported License. To view a copy of this license, visit http://creativecommons.org/licenses/by-nc-nd/3.0/ 